Published in final edited form as:

J Allergy Clin Immunol. 2017 May ; 139(5): 1692-1695.e6. doi:10.1016/j.jaci.2016.09.026.

\title{
Cross-Talk between Human Mast Cells and Epithelial Cells by IgE-mediated Periostin Production in Eosinophilic Nasal Polyps
}

\author{
Dae Woo Kim, MD, PhD ${ }^{a, b}$, Marianna Kulka, PhD ${ }^{c, d}$, Ara Jo, PhD $^{b}$, Kyoung Mi Eun, BSc ${ }^{a}$, \\ Narcy Arizmendi, PhD ${ }^{c, d}$, Brian P. Tancowny, $\mathbf{P h D}^{\mathrm{c}, \mathrm{d}}$, Seung-No Hong, $\mathbf{M D}^{\mathrm{a}}$, Jung Pyo Lee,

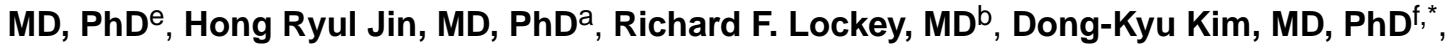 \\ and Seong $\mathbf{H}$ Cho, MD ${ }^{b}$, \\ aDepartment of Otorhinolaryngology-Head and Neck Surgery, Boramae Medical Center, Seoul \\ National University College of Medicine, Seoul, Korea \\ bDivision of Allergy-Immunology, Department of Internal Medicine, University of South Florida \\ Morsani College of Medicine, Tampa, Florida \\ 'Department of Medical Microbiology and Immunology, University of Alberta, Edmonton, Alberta \\ T6G 2E1, Canada \\ dNational Institute for Nanotechnology, National Research Council Canada, Edmonton, Alberta \\ T6G 2M9, Canada \\ eDepartment of Internal Medicine, Boramae Medical Center, Seoul National University College of \\ Medicine, Seoul, Korea \\ fDepartment of Otorhinolaryngology-Head and Neck Surgery, Chuncheon Sacred Heart Hospital \\ and Nano-Bio Regenerative Medical Institute, Hallym University College of Medicine, Chuncheon, \\ Republic of Korea
}

\section{To the Editor}

Periostin, an extracellular protein, has emerged as a novel mediator of allergic diseases and plays an important role in tissue remodeling. Serum periostin, as a biomarker, is elevated in severe eosinophilic asthma and aspirin-exacerbated respiratory disease ${ }^{1}$ and levels can predict the development of airflow limitation in asthmatic patients on an inhaled

Corresponding author: Seong H Cho, MD, Division of Allergy-Immunology, Department of Internal Medicine, 13000 Bruce B. Downs Blvd (111D), Tampa, FL 33612, Tel: 813-972-7631, Fax: 813-910-4041, scho2@ health.usf.edu. Dong-Kyu Kim, MD, PhD, Assistant professor, Department of Otorhinolaryngology-Head and Neck Surgery, Chuncheon Sacred Heart Hospital and Nano-Bio Regenerative Medical Institute, Hallym University College of Medicine, 153, Kyo-Dong, Chuncheon, 200-704, Republic of Korea. Tel: 82-33-240-5181, Fax: 82-33-241-2909, doctordk@naver.com.

Co-corresponding authors

Conflict of interest: The authors declare that they have no relevant conflicts of interest.

Declaration of all sources of funding:

This research was supported by a clinical research grant-in-aid from the Basic Science Research Program through the National Research Foundation of Korea (NRF) funded by the Ministry of Science, ICT and Future Planning (NRF-2015R1C1A1A01054573) and by grant support from NIH 1K23AI110731 and the American Heart Association 11SDG7590063.

Publisher's Disclaimer: This is a PDF file of an unedited manuscript that has been accepted for publication. As a service to our customers we are providing this early version of the manuscript. The manuscript will undergo copyediting, typesetting, and review of the resulting proof before it is published in its final citable form. Please note that during the production process errors may be discovered which could affect the content, and all legal disclaimers that apply to the journal pertain. 
corticosteroid $^{2}$ as well as responsiveness to omalizumab or lebrikizumab in uncontrolled severe allergic asthma. ${ }^{3,4}$ However, despite its clinical significance, the mechanism by which periostin regulates inflammation remains poorly understood in the pathogenesis of airway inflammatory diseases.

Chronic rhinosinusitis (CRS) is one of the most common chronic rhinologic diseases and can significantly reduce the quality of life of affected subjects. Increased periostin production in sinonasal tissues occurs in subjects with CRS, particularly those with nasal polyps (NP) and allergic fungal sinusitis. Periostin expression is also associated with CRS tissue eosinophil and disease severity. ${ }^{5,6}$ However, it is still unclear how periostin contributes to the pathophysiology of CRS with nasal polyps (CRSwNP). Therefore, the expression, cellular origin and function of periostin in NP tissues were investigated according to various subtypes of CRSwNP.

Sinonasal and polyp tissues were obtained from patients with CRS during routine functional endoscopic sinus surgery (Table EI). The diagnosis of CRS was based on a personal history, physical examination, nasal endoscopy, and CT findings of the sinuses according to the 2012 European position paper on rhinosinusitis and nasal polyps guidelines. NP were classified as eosinophilic NP (E-NP) if eosinophils comprised more than $10 \%$ of the inflammatory cell population. Detailed subject recruitment, experimental methods and statistical analyses were described in the Methods section in the Online Publication.

Uncinate process mucosa tissue was collected from control subjects (Control-UP), subjects with CRSsNP (CRSsNP-UP), and subjects with CRSwNP (CRSwNP-UP) and NP tissues were obtained from subjects with CRSwNP (NP) to examine the expression of periostin. Periostin mRNA and protein levels were significantly increased in NP compared to ControlUP, CRSsNP-UP, and CRSwNP-UP. Moreover, E-NP subjects had greater periostin mRNA expression and higher protein levels than those with NE-NP (Supplementary Fig. 1A and 1B). In addition, the Lund-Mackay CT score positively correlated with the concentration of periostin in NP homogenates in E-NP (Supplementary Fig. 1C; $r=0.542$, p=0.039).

Investigation of the relationship between periostin and major cytokines was performed according to the subtype of NP. E-NP showed that periostin protein levels were positively correlated with IL-5 $(r=0.488, p=0.039)$ and CCL11 $(r=0.540, p=0.030)$ and negatively associated with IL-17A ( $\mathrm{r}=-0.451, \mathrm{p}=0.071)$ and IFN- $\gamma(\mathrm{r}=-0.552, \mathrm{p}=0.024)$

(Supplementary Fig. 2A-D). There was no correlation of periostin with IL-4 and IL-13 and CXCL-8 in E-NP. However, the expression of periostin mRNA correlated with the mRNA expression of IL-13 ( $r=0.835$, $p<0.001$, data not shown) and IL-4 ( $r=0.350, p=0.049$, data not shown). For localization of periostin in NP, immunohistochemical staining (IHC) revealed that the expression of periostin was diffusely deposited on the extracellular matrix, fibroblasts, and subepithelial inflammatory cells (Fig. 1A). Major inflammatory cells, stained for periostin, were granulated cells, presumed to be mast cells (MCs) (Fig. 1B). Double IHC staining of tryptase and periostin confirms the expression of periostin in MCs (Fig. 1C). The number of double-positive cells was significantly increased in E-NP compared with NE-NP (Fig. 1D). The proportion of periostin positive MCs among total periostin positive cells is $34.2 \%$ (SD 11.9\%) in eosinophilic NP versus $10.3 \%$ (SD 7.0\%) in 
non-eosinophilic $\mathrm{NP}(\mathrm{N}=5$ for each, $p=0.016)$. In addition, a relationship between periostin and total IgE levels in E-NP homogenates was observed (Supplementary Fig. 2E; r=0.736, $\mathrm{p}=0.003$ ). LAD2 cells, a human mast cell line, were cultured and stimulated with IgE, IL-4, IL-13 and TNF- $a$ to confirm whether human MCs produce periostin and to identify the upstream inducers. Periostin gene expression was upregulated with $\operatorname{IgE}$ stimulation in a dose-dependent manner (up to 22.7 -fold in $0.5 \mu \mathrm{g} / \mathrm{mL}$ of SA/IgE) and with IL-4 compared to the untreated controls (Fig. 1E). LAD2 cells were tested to see whether or not they secrete periostin in response to various stimuli. IgE-dependent activation induced periostin secretion up to 58-fold in $24 \mathrm{hr}$ (Fig. 1F). Periostin is reported to bind and signal through integrin aV, a heterodimeric integral membrane protein. ${ }^{7}$ Therefore, the number of integrin $\mathrm{aV}$-positive epithelial cells was measured in nasal tissues (Fig. 1G). Integrin a V-positive epithelial cells were significantly increased in NP and CRSwNP-UP compared with Control-UP. In NP, the number of integrin a V-positive epithelial cells was higher in E-NP than in NE-NP. A positive correlation was found between periostin levels and the number of integrin $a \mathrm{~V}$ positive epithelial cells in E-NP ( $\mathrm{r}=0.792, \mathrm{p}=0.005)$. The relationship between expression of integrin $\mathrm{aV}$ and innate Th2 cytokines, such as TSLP was investigated to test the effect of periostin on Th2 inflammation through integrin aV. TSLP was stained and evaluated in epithelial cells, since TSLP was time-dependently degraded by protease and undetectable in NP tissues by commercial ELISA kits. TSLP expression positively correlated with integrin $\mathrm{aV}$ expression and periostin levels (Fig. $1 \mathrm{H}$ and $1 \mathrm{I} ; \mathrm{r}=0.854, \mathrm{p}=0.0008 ; \mathrm{r}=0.742, \mathrm{p}=0.018$, respectively). Therefore, it was hypothesized that the periostin/integrin $a \mathrm{~V}$ pathway induces TSLP in the epithelium of E-NP. To test this hypothesis, NHBE cells were first cultured using a submerged culture technique and stimulated with periostin $(10 \mathrm{ng} / \mathrm{mL}, 100 \mathrm{ng} / \mathrm{mL})$ with/without IL-4 or IL-13. However, TSLP could not be detected in these samples (data not shown). TSLP is synergistically enhanced by a combination of IL-4 and dsRNA in airway epithelial cells. ${ }^{8}$ Poly(I:C) was therefore added in each experimental protocol and cells stimulated with a combination of IL-4 (or IL-13) and poly(I:C) produced detectable levels of TSLP (Fig. 1J). Adding periostin, $100 \mathrm{ng} / \mathrm{ml}$, to IL-4 (or IL-13) and poly(I:C) further enhanced the production of TSLP. In addition, treatment with anti-aVa3 and anti-aV $\beta 5$ inhibited periostin-induced enhancement of TSLP production (Fig. 1K and 1L).

This study is the first to suggest that MCs are a main cellular source of periostin. Immunostaining confirms that double positive $\left(\right.$ tryptase $^{+}$periostin ${ }^{+}$) cells exist in NPs. Moreover, levels of total IgE also positively correlated with periostin protein levels. We also show that IgE stimulation of LAD2 cells can induce periostin production. These findings mechanistically support a 2013 clinical trial which demonstrates that periostin is a marker of omalizumab responsiveness in subjects with uncontrolled severe asthma. ${ }^{3}$ IL-4 and IL-13 also upregulate periostin mRNA expression but fail to induce the release of periostin protein from the LAD2 cells. There was a correlation between IL-4/IL-13 and periostin in NP tissue samples only at the mRNA levels.

Periostin binds to several integrin molecules, including $a V \beta 1, a V \beta 3$, and $a \mathrm{~V} \beta 5$ on the epithelial cell surface. In this study, both periostin and integrin $a V$ were upregulated in E$\mathrm{NP}$ and their levels were positively correlated. Furthermore, both periostin and integrin aV expression levels correlated with TSLP production. Therefore, it was hypothesized that the periositn-integrin $a \mathrm{~V}$ pathway plays a role in TSLP production from airway epithelia. 
Epithelium-derived TSLP is known to be induced by viruses, TLR3 agonists, protease, and pro-inflammatory cytokines. ${ }^{8,9} \mathrm{IL}-1 \beta$ and TNF- $\alpha$ regulate TSLP transcript expression in an $\mathrm{NF}-\kappa \mathrm{B}$-dependent manner, which might be a common regulator with the periostin-integrin aV pathway. ${ }^{7}$ Therefore, both signals were expected to induce increased TSLP production. However, Th2 cytokine signals are required for periostin to function as a TSLP inducer. Tyrosine-phosphorylated STAT6 and NF- $\kappa$ B can directly bind each other, and their interaction synergistically activates IL-4-induced genes and activators of NF- $\mathrm{kB} .{ }^{10}$ Therefore, periostin might enhance synergistic activity of Th2 cytokine-induced STAT6 and dsRNA-induced NF- $\kappa B$ to be a TSLP inducer in E-NP. This study suggests that periostin can be produced by MCs and can act on epithelial cells via integrin binding-activation, resulting in TSLP secretion. Afterwards, epithelial-derived TSLP activates MCs to produce IL-5 and induces Th2 inflammation via dendritic cells (Supplementary Fig. 3). These findings suggest that periostin may be a novel biomarker for E-NP and that periostin inhibition may offer a new strategy to treat E-NP.

\section{METHODS}

\section{Patients and tissue samples}

Sinonasal and polyp tissues were obtained from patients with CRS during routine functional endoscopic sinus surgery. All subjects provided written informed consent for study participation, and the study was approved by the internal review board of the Seoul National University Hospital, Boramae Medical Center (No. 06-2012-109). The diagnosis of CRS was based on personal history, physical examination, nasal endoscopy, and CT findings of the sinuses according to the 2012 European position paper on rhinosinusitis and nasal polyps (EPOS) guidelines. Exclusion criteria were as follows: (1) younger than 18 years of age, (2) prior treatment with antibiotics, systemic or topical corticosteroids, or other immunemodulating drugs for 4 weeks before surgery, and (3) unilateral rhinosinusitis, antrochoanal polyp, allergic fungal sinusitis, cystic fibrosis, or immotile ciliary disease. Control tissues were obtained during other rhinologic surgeries, such as skull base, lacrimal duct, or orbital decompression surgery, from patients without any sinonasal diseases. Uncinate process (UP) tissue was obtained from control subjects and those with CRSsNP or CRSwNP. NP tissue in patients with CRSwNP also was evaluated. Each sample was divided into three parts: one third was fixed in $10 \%$ formaldehyde and embedded in paraffin for histological analysis, another third was immediately frozen and stored at $-80^{\circ} \mathrm{C}$ for subsequent isolation of mRNA, and the final third was submersed in $1 \mathrm{~mL}$ phosphate-buffered saline (PBS) supplemented with $0.05 \%$ Tween-20 (Sigma-Aldrich, St Louis, MO) and 1\% PIC (SigmaAldrich) per $0.1 \mathrm{~g}$ of tissue. The latter tissue was homogenized with a mechanical homogenizer at 1,000 rpm for $5 \mathrm{~min}$ on ice. After homogenization, the suspensions were centrifuged at 3,000 rpm for $10 \mathrm{~min}$ at $4^{\circ} \mathrm{C}$ and the supernatants were separated and stored at $-80^{\circ} \mathrm{C}$ for further analysis of cytokines and other inflammatory mediators. The atopic status of study subjects was evaluated using the ImmunoCAP ${ }^{\circledR}$ assay (Phadia, Uppsala, Sweden) to detect IgE antibodies against six mixtures of common aeroallergens (house dust mites; molds; trees; weeds and grass pollen; and animal danders). Subjects were considered atopic if the allergen-specific IgE level was greater than $3.51 \mathrm{KU} / \mathrm{L}$ to any one or more of the allergens. Also, total IgE levels in nasal tissue homogenates were measured using the 
ImmunoCAP ${ }^{\circledR}$ assay. A diagnosis of asthma was based on the medical history and lung function analysis, including challenge tests by an allergist. In this study, CRSwNP were classified as eosinophilic NP (E-NP) if eosinophils comprised more than $10 \%$ of the inflammatory cell population and as non-eosinophilic NP (NE-NP) if eosinophils comprised less than $10 \%$ of the inflammatory cells.

\section{Immunohistochemistry (IHC)}

Single immunohistochemical staining was performed using the polink-2 plus polymerized horseradish peroxidase (HRP) broad DAB-Detection System (Golden Bridge International Labs., WA). Briefly, after deparaffinization, sections were incubated in $3 \%$ hydrogen peroxidase to inhibit endogenous peroxidases. Heat-induced epitope retrieval was then performed by microwa Ving samples in $10 \mathrm{mmol} / \mathrm{L}$ citrate buffer ( $\mathrm{pH} \mathrm{6.0)}$. The sections were incubated for 60 minutes at room temperature in a primary antibody. The primary antibodies were rabbit anti-periostin (1:2000; Abcam, Cambridge, UK), rabbit anti-CD51 as marker for integrin $\mathrm{aV}$ (1:150; Abcam) and TSLP (1:1000; Abcam). The sections were incubated in broad antibody enhancer and polymer-HRP and then stained with the DAB Detection System. Finally, slides were counterstained with hematoxylin. The numbers of positive cells were counted in the five densest visual fields (400x) by two independent observers, and the a Verage values were determined. Sequential double IHC was employed using polymer-HRP and alkaline phosphatase (AP) kits to detect mouse anti-mast-cell tryptase (1:500; Abcam) and rabbit anti-periostin primary antibodies for human tissue with permanent-Red and Emerald (Polink DS-MR-Hu C2 Kit; Golden Bridge International Labs).

\section{qRT-PCR analysis}

Total RNA was extracted from tissue samples using the TRI reagent (Invitrogen, Carlsbad, CA). One microgram total RNA was reverse transcribed to cDNA using the cDNA Synthesis Kit (amfiRivert Platinum cDNA Synthesis Master Mix, GenDEPOT). Quantitative real-time PCR (qRT-PCR) was performed. For analysis of POSTN (Hs01566734_m1), CD51 (integrin aV, Hs00233808_m1), IL-4 (Hs00174122_m1), IL-5 (Hs01548712_g1), IL-13 (Hs00174379_m1), IL-17A (Hs00174383_m1), IFN- $\gamma$ (Hs00989291_m1), TSLP (Hs00263636_m1), IL-25 (Hs03044841_m1), IL-33 (Hs00369211_m1) and GAPDH (Hs02758991_g1), pre-developed assay reagent (PDAR) kits of primers and probes were purchased from TaqMan assays (Life Technologies Korea, Seoul, Korea). Pre-developed assay reagent kits containing primers and probes were purchased from Applied Biosystems (Foster City, CA). Expression of GAPDH was used as an internal control for normalization. Cycling conditions were as follows: $95^{\circ} \mathrm{C}$ for $5 \mathrm{~min}$ followed by 60 cycles at $95^{\circ} \mathrm{C}$ for 15 $\mathrm{sec}, 60^{\circ} \mathrm{C}$ for $20 \mathrm{sec}$, and $72^{\circ} \mathrm{C}$ for $20 \mathrm{sec}$. To analyze the data, Sequence Detection Software version 1.9.1 (Applied Biosystems) was utilized. Relative gene expression was calculated using the comparative $2^{-\Delta \Delta C T}$ method.

\section{Measurement of cytokines and total IgE in tissue homogenates}

The protein concentrations for tissue extracts were determined using the Pierce 660nm Protein Assay Kit (Thermo Scientific Inc., NY). Samples were thawed at room temperature and vortexed to ensure well-mixed sample. Tissue homogenates were then assayed for periostin proteins by using commercially available ELISA kits (R\&D systems, MN). 
Multiple cytokine analysis kits (IL-4, IL-5, IL-13, IL-17A, IL-25, IL-33, CXCL-8, CCL-11, and IFN- $\gamma$ ) were obtained from R\&D systems (Cat. No. LMSAHM) and data collected using Luminex 100 (Luminex, Austin, TX). Data analysis was performed using the MasterPlex QT version 2.0 (MiraiBio, Alameda, CA). Total IgE levels in nasal tissue homogenates were measured by using the ImmunoCAP ${ }^{\circledR}$ assay. All kinds of assays were run in duplicate according to the manufacturers' protocol. All the protein levels in the tissue homogenate were normalized to the concentration of total protein.

\section{Human mast cell culture and measurement of cytokine production}

LAD2 mast cells (MCs) were cultured in serum-free media (StemPro-34 SFM, Life Technologies) supplemented with $2 \mathrm{mM} \mathrm{L-glutamine,} 100 \mathrm{U} / \mathrm{ml}$ penicillin, $50 \mu \mathrm{g} / \mathrm{ml}$ streptomycin and $100 \mathrm{ng} / \mathrm{ml}$ stem cell factor (SCF). The cell suspensions were cultured at a density of $10^{5}$ cells $/ \mathrm{ml}$ and maintained at $37^{\circ} \mathrm{C}$ and $5 \% \mathrm{CO} 2$. LAD2 cells were suspended at $0.2 \times 10^{6}$ cells per well in fresh media containing $100 \mathrm{ng} / \mathrm{mL}$ of SCF, and sensitized with 0.5 $\mu \mathrm{g} / \mathrm{mL}$ of biotinylated IgE (bIgE; Abbiotec, San Diego, CA) overnight at $37^{\circ} \mathrm{C}$. Sensitized cells were resuspended at $0.5 \times 10^{6}$ cells $/ \mathrm{mL}$ in fresh media and stimulated with $0.05-0.5$ $\mu \mathrm{g} / \mathrm{mL}$ streptavidin (Life Technologies), recombinant human IL-4 (10 ng/ml), recombinant human IL-13 $(10 \mathrm{ng} / \mathrm{ml})$ or recombinant human TNF $(10 \mathrm{ng} / \mathrm{mL})$ for $3 \mathrm{hr}$ at $37^{\circ} \mathrm{C}$. RNA was isolated using Trizol. Reverse transcription of total RNA and amplification of target mRNA were performed using the iScript Select cDNA synthesis kit from (BioRad). The gene target, periostin was amplified using gene specific primers, designed for end point evaluation using Primer Express software (Perkin Elmer). The primer sequences for periostin were as follows: 5' -GATGCAGTGCCTGTGGAAATA-3' Forward, 5' CTGAGAACGACCTTCCCTTAATC- $3^{\prime}$ Reverse, Housekeeping gene, GAPDH primer set: 5'-GAAGGTGAAGGTCGGAGTC-3' Forward, 5'-GAAGATGGTGATGGGATTTC-3' Reverse. qRT-PCR analysis was performed using Perfecta Sybr supermix from Quanta Bioscience (VWR). The reaction conditions were as follows: $95^{\circ} \mathrm{C}$ for $3 \mathrm{~min}$ (Hold) 1 cycle and $95^{\circ} \mathrm{C}$ for $10 \mathrm{sec}, 55^{\circ} \mathrm{C}$ for $30 \mathrm{sec}, 72^{\circ} \mathrm{C}$ for $60 \mathrm{sec}$ (cycling) 40 cycles. Resulting PCR products were measured by the sequence detector Qiagen Rotor-Gene Q (Qiagen).

Quantitation of gene expression by real-time RT-PCR was evaluated using the copy number method. Secreted periostin was measured in cell supernatants using a sensitive and specific ELISA according to the manufacturer's instructions (BioVision, Inc). The detection limit for the assay was $15 \mathrm{pg} / \mathrm{ml}$.

\section{Human bronchial epithelial cell culture}

Normal human bronchial epithelial (NHBE) cells were purchased from Lonza (Walkersvile, MD) and cultured in serum-free bronchial epithelial growth medium (BEGM, Lonza) at $37^{\circ} \mathrm{C}$ in a humidified environment containing 5\% CO2. NHBE cells were plated in 12-well culture plates coated with collagen (Corning, NY) and grown 40-50\% confluence. Before treatment, NHBE cells were maintained in BEGM without hydrocortisone for at least 2 days. NHBE cells were treated with recombinant human IL-4 or IL-13 $(100 \mathrm{ng} / \mathrm{ml}$, each; R\&D systems, Minneapolis, MN) with or without periostin (10 or $100 \mathrm{ng} / \mathrm{ml}$; R\&D systems) for 72 hours. Additionally, in each experiment, NHBE cells were stimulated with poly(I:C) ( $5 \mu \mathrm{g} / \mathrm{ml}$; InvivoGen, San Diego, CA) at 1 hour after treatment with IL-4, IL-13, and/or periostin. Anti-integrin $a V a 3$ and anti-integrin $\alpha \mathrm{V} \beta 5(2.5 \mu \mathrm{g} / \mathrm{ml} ; \mathrm{R} \& \mathrm{D}$ systems) were added 
to confirm reversibility of periostin-induced TSLP production. Cell culture supernatants were collected and used for TSLP protein ELISA (R\&D systems, Minneapolis, MN).

\section{Statistical analysis}

Statistical analyses were performed using IBM SPSS 21 (SPSS, Inc., Chicago, IL) and GraphPad Prism software 6.0 (GraphPad software Inc, La Jolla, CA). The Kruskal-Wallis test and the Mann-Whitney $U$-test with a 2-tailed test for unpaired comparisons were used. For comparisons between groups, the Kruskal-Wallis test was used to establish significant intergroup variability. The Mann-Whitney $U$-test was then used for between-group comparisons. The Pearson correlation test was also used to determine variable relationships. If the data were not normally distributed, the Spearman correlation coefficient was utilized. The significance level was set at an a value of 0.05 .

\section{Supplementary Material}

Refer to Web version on PubMed Central for supplementary material.

\section{Acknowledgments}

Authors would like to express thanks to Priyanka Pundir for providing technical assistance.

\section{Abbreviations used}

$\begin{array}{ll}\text { CCL } & \text { C-C motif ligand } \\ \text { CRS } & \text { Chronic rhinosinusitis } \\ \text { CRSwNP } & \text { Chronic rhinosinusitis with nasal polyps } \\ \text { CRSsNP } & \text { Chronic rhinosinusitis without nasal polyps } \\ \text { CXCL } & \text { C-X-C motif ligand } \\ \text { E-NP } & \text { Eosinophilic nasal polyps } \\ \text { HPF } & \text { High power field } \\ \text { IHC } & \text { Immunohistochemical staining } \\ \text { IFN } & \text { Interferon } \\ \text { IL } & \text { Interleukin } \\ \text { LAD2 } & \text { Laboratory of allergic diseases } \\ \text { MCs } & \text { Mast cells } \\ \text { NE-NP } & \text { Non-eosinophilic nasal polyps } \\ \text { NP } & \text { Nasal polyp } \\ \text { TSLP } & \text { Thymic stromal lymphopoietin }\end{array}$




\section{References}

1. Kim MA, Izuhara K, Ohta S, Ono J, Yoon MK, Ban GY, et al. Association of serum periostin with aspirin-exacerbated respiratory disease. Ann Allergy Asthma Immunol. 2014; 113:314-20. [PubMed: 25037608]

2. Kanemitsu Y, Matsumoto H, Izuhara K, Tohda Y, Kita H, Horiguchi T, et al. Increased periostin associates with greater airflow limitation in patients receiving inhaled corticosteroids. J Allergy Clin Immunol. 2013; 132:305-12. e3. [PubMed: 23791506]

3. Hanania NA, Wenzel S, Rosen K, Hsieh HJ, Mosesova S, Choy DF, et al. Exploring the effects of omalizumab in allergic asthma: an analysis of biomarkers in the EXTRA study. Am J Respir Crit Care Med. 2013; 187:804-11. [PubMed: 23471469]

4. Corren J, Lemanske RF, Hanania NA, Korenblat PE, Parsey MV, Arron JR, et al. Lebrikizumab treatment in adults with asthma. N Engl J Med. 2011; 365:1088-98. [PubMed: 21812663]

5. Laury AM, Hilgarth R, Nusrat A, Wise SK. Periostin and receptor activator of nuclear factor kappaB ligand expression in allergic fungal rhinosinusitis. Int Forum Allergy Rhinol. 2014; 4:716-24. [PubMed: 25060295]

6. Wang M, Wang X, Zhang N, Wang H, Li Y, Fan E, et al. Association of periostin expression with eosinophilic inflammation in nasal polyps. J Allergy Clin Immunol. 2015; 136:1700-3. e1-9. [PubMed: 26521039]

7. Masuoka M, Shiraishi H, Ohta S, Suzuki S, Arima K, Aoki S, et al. Periostin promotes chronic allergic inflammation in response to Th2 cytokines. J Clin Invest. 2012; 122:2590-600. [PubMed: 22684102]

8. Kato A, Favoreto S Jr, Avila PC, Schleimer RP. TLR3- and Th2 cytokine-dependent production of thymic stromal lymphopoietin in human airway epithelial cells. J Immunol. 2007; 179:1080-7. [PubMed: 17617600]

9. Lee HC, Headley MB, Loo YM, Berlin A, Gale M Jr, Debley JS, et al. Thymic stromal lymphopoietin is induced by respiratory syncytial virus-infected airway epithelial cells and promotes a type 2 response to infection. J Allergy Clin Immunol. 2012; 130:1187-96. e5. [PubMed: 22981788]

10. Shen $\mathrm{CH}$, Stavnezer J. Interaction of stat6 and NF-kappaB: direct association and synergistic activation of interleukin-4-induced transcription. Mol Cell Biol. 1998; 18:3395-404. [PubMed: 9584180] 

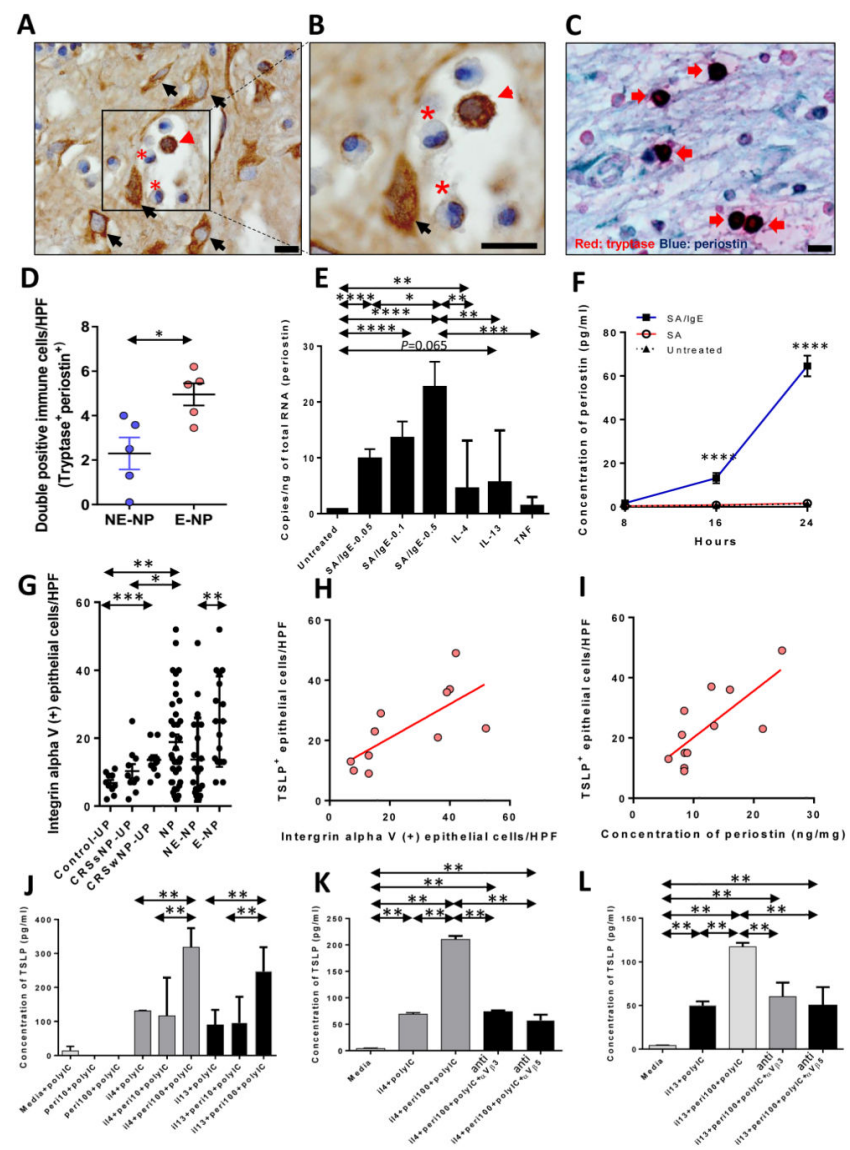

Figure 1. Cross-talk between human mast cells and epithelial cells in eosinophilic nasal polyps $(\mathbf{A}, \mathbf{B})$ IHC detection of periostin was performed within the NP tissues from patients with CRSwNP (eosinophil, asterisk; mast cell, red arrow head; fibroblast, black arrow). Black scale bar $=10 \mu \mathrm{m}$. (C) Representative double immunostaining (red: tryptase and blue:

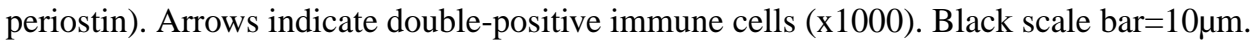
(D) Counts of double-positive cells in NE-NP and E-NP ( $n=5$ for each group). (E) Periostin mRNA expression was measured by qRT-PCR in LAD2 cells stimulated with IgE, IL-4, IL-13 and TNF-a ( $n=9$ for each group). (F) Periostin protein expression stimulated by $\operatorname{IgE}$ ( $n=3$ for each group). (G) Number of integrin a V-positive epithelial cells per 100 cells was determined and averaged from three different areas of epithelium ( $\mathrm{n}=10$ for Control-UP, n=10 for CRSsNP-UP, $n=10$ for CRSwNP-UP, and n=37 for CRSwNP-NP) in IHC assays of tissue sections. The number of integrin aV-positive inflammatory cells was counted from five of the densest areas (HPF; x400) and averaged for each group. (H) Correlation between integrin $\mathrm{aV}$ and TSLP at the protein level. (I) Correlation between periostin and TSLP at the protein level. (J) Periostin-induced TSLP production in NHBE cells after Th2 cytokine and Poly(I:C) treatment ( $\mathrm{n}=3$ for each group). (K, L) Periostin-induced TSLP production was reversed by anti-integrin $a \mathrm{~V} \beta 3(\mathrm{~K})$ and anti- integrin $a \mathrm{~V} \beta 5(\mathrm{~L})(\mathrm{n}=3$ for each group). $* P<0.05, * * P<0.01, * * * P<0.001$, and $* * * * P<0.0001$ using the Mann-Whitney $U$-test. 